\title{
Electronic Case Report Form Technical Design Document
}

National Cancer Institute

\section{Source}

National Cancer Institute. Electronic Case Report Form Technical Design Document. NCI

Thesaurus. Code C125437.

Document containing the design elements of the electronic case report form (eCRF)

system used in a clinical trial. 